\title{
Interactive effects of fire and large herbivores on web-building
}

\section{spiders}

C. N. Foster ${ }^{*}$, P. S. Barton ${ }^{a, b}$, J. T. Wood ${ }^{a}$ and D. B. Lindenmayer ${ }^{a, b, c}$

${ }^{\text {a }}$ Fenner School of Environment and Society, The Australian National University, Acton, ACT, 2601, Australia.

${ }^{\mathrm{b}}$ Australian Research Council Centre of Excellence for Environmental Decisions and the National Environmental Research Program Environmental Decisions Hub, The Australian National University, Acton, ACT, 2601, Australia.

${ }^{\mathrm{c}}$ The Long-term Ecological Research Network, The Australian National University, Acton, ACT, 2601, Australia.

${ }^{*}$ Corresponding author - E: claire.foster@anu.edu.au, T: +61 261253569

Author Contributions: CNF, DBL, PSB and JTW designed the experiments. CNF collected data. CNF, PSB and JTW analysed the data. CNF drafted the manuscript, all authors contributed to revisions. 


\section{Abstract}

2 Altered disturbance regimes are a major driver of biodiversity loss worldwide. Maintaining or

3 recreating natural disturbance regimes is therefore the focus of many conservation programs.

4 A key challenge, however, is to understand how co-occurring disturbances interact to affect

5 biodiversity. We experimentally tested for the interactive effects of prescribed fire and large

6 macropod herbivores on the web-building spider assemblage of a eucalypt forest understorey,

7 and investigated the role of vegetation in mediating these effects using path analysis. Fire had

8 strong negative effects on the density of web-building spiders, which was partly mediated by

9 effects on vegetation structure, while negative effects of large herbivores on web density were

10 not related to changes in vegetation. Fire amplified the effects of large herbivores on spiders,

11 both via vegetation-mediated pathways, and by increasing herbivore activity. The importance

12 of vegetation-mediated pathways and fire-herbivore interactions differed for web density and

13 richness, and also differed between web types. Our results demonstrate that for some groups

14 of web building spiders, the effects of co-occurring disturbance drivers may be mostly

15 additive, whereas for other groups, interactions between drivers can amplify disturbance

16 effects. In our study system, the use of prescribed fire in the presence of high densities of

17 herbivores could lead to reduced densities and altered composition of web-building spiders,

18 with potential cascading effects through the arthropod food web. Our study highlights the

19 importance of considering both the independent and interactive effects of disturbances, as

20 well as the mechanisms driving their effects, in the management of disturbance regimes.

22 Keywords: Araneae, browsing, disturbance interaction, grazing, synergistic effects 


\section{Introduction}

Disturbance regimes drive the structure and function of ecosystems worldwide, and altered disturbance regimes are an important cause of biodiversity loss (Sinclair and Byrom 2006). Maintaining or recreating appropriate disturbance regimes is therefore the focus of many conservation and restoration programs (Hobbs and Huenneke 1992; Halme et al. 2013).

\section{Two of the most common and widely studied disturbance drivers in terrestrial systems are} herbivory and fire (Bond and Keeley 2005; Danell et al. 2006). Browsing or grazing by large mammalian herbivores has been shown to shape the structure and function of ecosystems, from plant and animal communities, through to nutrient cycles and even climate (Côté et al. 2004; Danell et al. 2006; Foster et al. 2014). Fire is an episodic disturbance, and the frequency, intensity and spatial extent of fires also drives the structure and function of ecosystems (Thonicke et al. 2001; Bond and Keeley 2005). Both of these disturbances can affect biota either directly (e.g. through direct mortality), or indirectly (e.g. by modifying habitat), or both (Thonicke et al. 2001; Côté et al. 2004). A key mechanism linking both large herbivores and fire to effects on biological communities is via changes in vegetation structure and complexity (Bond and Keeley 2005; Foster et al. 2014).

As disturbances rarely occur in isolation, understanding how disturbance drivers interact to affect biota is critical for effective conservation management (Wisdom et al. 2006; Didham et al. 2007; Mantyka-pringle et al. 2012). Although the ecological effects of disturbance have been widely studied, investigations of the interactive effects of disturbance drivers are much less common (Wisdom et al. 2006; Didham et al. 2007; Foster et al. 2014). Interactions between fire and herbivory have been reported in a range of ecosystems, and can occur in a number of ways. For example, patterns and intensity of herbivory can affect fuel loads and 
hence modify the spatial extent or intensity of fire (Wisdom et al. 2006; Kimuyu et al. 2014). Similarly, as many herbivores are attracted to the new growth available in recently burnt areas, fire can affect the spatial distribution and intensity of herbivory (Allred et al. 2011).

Fire and herbivory also can interact via what is termed an interaction modification, where fire changes the mode of action or per-unit effect of herbivory on organisms (sensu Didham et al. 2007). For example, Royo et al. (2010) found that moderate levels of deer browsing increased understorey plant richness in burnt deciduous forest, but not in unburnt forest. Interactions between disturbance drivers can be synergistic (i.e. effects magnified, e.g. Barton et al. 2011) or antagonistic (i.e. effects diminished or reversed, e.g. Matlack et al. 2001), and by definition, differ from what would be predicted from the additive effects of each driver occurring in isolation (Didham et al. 2007; Crain et al. 2008).

Most studies of fire $\times$ large herbivore interactions have investigated effects on vegetation (e.g. Royo et al. 2010; Kerns et al. 2011), and to date only a small number of studies have investigated how these interactions affect animal assemblages. Among these studies, there appears to be a consistency between vegetation and animal responses; most studies which report interactive effects on animals also report interactive effects on vegetation (e.g. Matlack et al. 2001, deer mice; Bailey and Whitham 2002, arthropods), while studies which find no interactive effects on animals also find no interactive effects on vegetation (e.g. Jonas and Joern 2007, grasshoppers; Underwood and Christian 2009, ants).

Web-building spiders are a group of animals that have been found to respond to both fire (Buddle et al. 2000) and large herbivores (Miyashita et al. 2004; Warui et al. 2005), but the responses of these spiders to fire-herbivore interactions have not previously been studied. Web-building spiders respond strongly to changes in vegetation structure (Langellotto and 
Denno 2004), and are the dominant invertebrate predators in terrestrial food webs (Riechert and Lockley 1984; Carter and Rypstra 1995). Therefore, disturbance-induced changes in vegetation structure may modify spider densities, which could have important consequences for trophic dynamics (Schmitz 2008). In addition, different types of web-builders may differ in their response to habitat complexity, for example, Halaj et al. (2000) found that sheet weaving spiders, which build complex three-dimensional webs, responded more negatively to habitat simplification than orb-weaving spiders. As different types of web-builders target different prey items (Nyffeler 1999), changes in vegetation structure also may affect food web structure by altering the composition of the predator guild. However, as disturbance effects can cascade through ecosystems via both trophic and non-trophic pathways (Ohgushi 2005), it is important to understand the extent to which disturbance effects are mediated by changes in vegetation, and whether managing disturbances to maintain vegetation condition will also cater for the requirements of fauna (Clarke 2008).

In this study, we tested for the effects of fire, large macropod herbivores and their interaction on the web-building spider assemblage of a eucalypt forest understory. We used a randomised, blocked experiment, combining prescribed fire and herbivore exclusion treatments, to address three questions: (1) Do large herbivores and fire interact to affect the density or richness of web-building spiders? (2) To what extent are the effects of these disturbances mediated by changes in vegetation? And (3) Do these effects differ between different types of web-builders? We predicted that both fire and large herbivores would reduce web-building spider density and richness by reducing the structural complexity of vegetation, with sheet web-builders responding most strongly to vegetation simplification. 


\section{Materials and methods}

\section{Study site}

We conducted our study in Booderee National Park (BNP); a $~ 6500$ ha peninsula in southeastern Australia $\left(35^{\circ} 10^{\prime} \mathrm{S}, 150^{\circ} 40^{\prime} \mathrm{E}\right.$, see Online Resource 1). We established sites within the Eucalyptus pilularis forest of BNP, which is the most widespread vegetation type in the park (Barton et al. 2014). An intensive baiting program targeting the introduced red fox (Vulpes vulpes) has been in place in BNP since 1999 to protect native small and medium-sized mammal species from predation (Dexter et al. 2012). Loss of native predators and a lack of human hunting mean that without foxes, predation pressure on native macropod herbivores is low (Lindenmayer et al. 2014). Over the last decade, there has been a tenfold increase in the numbers of these herbivores in BNP (predominantly Wallabia bicolor, a generalist browser and Macropus giganteus, a grazer, Family Macropodidae) (Dexter et al. 2012; Lindenmayer et al. 2014). A short-term exclosure trial has indicated that this high abundance of native herbivores could be driving a shift in vegetation composition (Dexter et al. 2013). As prescribed fire is commonly used in eucalypt forests to reduce the risk of high intensity wildfire, promote regeneration of senescing vegetation, and/or increase habitat heterogeneity (Williams et al. 1994), it is important to understand how fire interacts with high abundances of herbivores to affect biodiversity.

\section{Study design}

We tested the interactive effects of prescribed fire and large herbivores on understorey vegetation and web-building spiders using a randomised blocked experiment. We combined three levels of herbivore treatment (open, partial and exclosure) and two levels of burning treatment (burnt and unburnt) in a factorial design. We replicated each of these six treatment combinations across four experimental blocks to give a total of 24 sites (Online Resource 1). 
122 We created the herbivore treatments by using exclosure fences to reduce the density of

123 macropods within 0.125 ha $(25 \mathrm{~m} \times 25 \mathrm{~m})$ plots, to produce three treatments: full herbivory

124 (open treatment), intermediate herbivory (partial treatment - plots were fenced but gates

125 opened and closed at two month intervals to create a lower browsing pressure) and no

126 herbivory (exclosure treatment). Exclosure fences were constructed in June 2012 using $1.1 \mathrm{~m}$

127 tall wire fencing, which we found to be effective at excluding macropods (see Results).

128 Smaller animals were observed to move freely through the fence, and other large animals are

129 rare in the park, so effects of exclosure fences were assumed to occur primarily via their effect

130 on macropods. For the burning treatments, small $(50 \times 50 \mathrm{~m})$, low-intensity burns were

131 conducted across half of the herbivory treatment sites in August 2012.

\section{Data collection}

134 We sampled spider webs and vegetation within four $3 \times 3 \mathrm{~m}$ plots within each site (one in

135 each of the four quarters of the site). Data were collected three months post-fire (November 136 2012) and 15 months post-fire (November 2013). Plots were established at least $1.5 \mathrm{~m}$ from

137 the edge of the site.

139 We counted spider webs as a surrogate measure for the web-building spider assemblage. This

140 method was described and tested by Gollan et al. (2010), who found that the diversity of web-

141 types (based on web architecture) was strongly correlated with the diversity of spider genera

142 in a site. As the richness of spider genera can be a viable surrogate for the species richness of

143 spiders (Foord et al. 2013), this method allowed us to assess compositional and diversity

144 responses of spiders, in addition to density responses. We used vaporised water, applied with

145 a pressurised spray mister, to assist in locating webs, and counted and identified all spider

146 webs within each of the four plots in each site. Each web was assigned to one of 32 web types 
147 based on their architecture, according to the key of Smith (2008) (see Fig. 1 for examples).

148 From this, we generated measures of web density (number of webs per $3 \times 3 \mathrm{~m}$ plot), web

149 richness (the number of different web types per plot) and web composition (the assemblage

150 composition of web types) for each plot. To minimise variation due to weather conditions,

151 surveys were delayed for 48 hours following strong wind or rain to allow spiders to rebuild

152 damaged webs.

153

154 We recorded the following vegetation variables from each plot; total understorey foliage

155 projective cover (the proportion of ground area covered by foliage held vertically above it,

156 Specht and Morgan 1981), foliage projective cover of vascular plants by life-form,

157 understorey height (measured at 10 evenly spaced locations per plot using the stick and foam

158 disc method of Smit et al. (2001), disc $100 \mathrm{~mm}$ diameter, $4.7 \mathrm{~g}$ weight), litter depth (measured

159 at 10 evenly spaced locations per plot) and stem density (number of live woody stems at

160 ground level within a $1 \times 1 \mathrm{~m}$ sub-plot). Life-forms were grouped into the broad structural

161 categories of ferns, grasses (Poaceae), herbs (including forbs and climbers), sedges (which

162 included grass-like perennial herbs) and shrubs (including sub-shrubs and tree seedlings).

163

164 We measured the effects of burning and the herbivory treatments on herbivore activity using

165 scat (pellet) counts. Scat counts are a commonly used method to assess the comparative

166 density of macropod herbivores between sites (e.g. Howland et al. 2014; Pedersen et al.

167 2014). We counted the number of macropod scats along two $25 \times 2 \mathrm{~m}$ transects $\left(100 \mathrm{~m}^{-2}\right)$ in

168 each site approximately every two months from August 2012 to December 2013. Counts from

169 the two transects were summed to give one count per site. We removed scats from transect

170 lines on each sampling event to avoid double counting. For each site, we summed the count 
171 preceding and that following the spider web counts to give an approximate index of herbivore

172 activity in each site at the time of the web count.

173

174

\section{Data analysis}

\section{Effects of fire and large herbivores on web density and richness}

We used generalised multi-level path models (Shipley 2009) to test the effects of fire and large herbivores on spider web density and richness, and the extent to which these effects were mediated by vegetation changes. Generalised multi-level path analysis uses directionalseparation (d-sep) tests to assess the goodness of fit of a hypothesised causal diagram to the patterns of dependence and independence within a dataset (Shipley 2002). This analysis is based on a structural equation modelling (SEM) framework, but has been generalised to accommodate hierarchical designs and non-normal response variables (Shipley 2009).

We hypothesised that the effects of fire, herbivores and their interaction on spiders would be largely vegetation-mediated, but would also occur via other mechanisms that operate independently of vegetation structure (Fig. 2). Our rationale for the construction of this causal model was as follows: Fire can affect spiders through changes in vegetation structure (Brennan et al. 2006), or via other mechanisms that operate independently of vegetation (the direct fire-spider pathway in Fig. 2), such as fire-induced mortality (Bell et al. 2001), or changes in prey availability (York 1999). Similarly, large herbivores have been found to affect spiders by modifying vegetation structure (Miyashita et al. 2004), but could also affect spiders through other mechanisms (the direct herbivore-spider pathway in Fig. 2) such as physical disturbance of webs (Chmiel et al. 2000), or changes to key resources such as arthropod prey (Foster et al. 2014). We also identified three possible pathways by which fire could interact with large herbivores to affect spiders; (1) a chain effect, where fire attracts 
196 herbivores to burnt areas, increasing the level of herbivore activity in burnt sites (Allred et al.

197 2011), (2) an interaction modification, where fire alters plant traits, modifying the effect of

198 herbivores on vegetation (Augustine and McNaughton 1998), or (3) an interaction

199 modification where fire increases the vulnerability of web spiders to other impacts of large

200 herbivores (e.g. by reducing prey availability, increasing the likelihood of spiders abandoning

201 webs after physical disturbance, Chmiel et al. 2000).

203 Confirmatory path analysis does not allow for reciprocal effects among variables (Shipley 2009), but a number of vegetation variables we measured were likely to be reciprocally related (for example, high grass cover would lead to low average understory height and low

206 stem density in a site). Therefore, we selected three vegetation variables that were not correlated with each other, but made up a large component of the vegetation and were correlated with other vegetation variables, to include in the path analysis (cover of shrubs, sedges and ferns). While this approach avoided reciprocity between variables, in excluding some vegetation variables, we potentially omitted variation in vegetation structure that could

211 explain spider responses to disturbance. Therefore, we also conducted a sensitivity analysis

212 (sensu Ruffell et al. 2014) to test whether including additional vegetation variables in our path model would increase the extent to which disturbance effects were mediated by vegetation

214 (Online Resource 2). To do this, we used principal components analysis to reduce our nine 215 vegetation variables to seven orthogonal components, and used these at the measures of 216 vegetation structure in our path analysis. We did not use principal components in the main 217 analysis as principal components are less correlated than would be expected by chance, and 218 including them in the path analysis would reduce our chance of rejecting an incorrectly 219 specified path model (Ruffell et al. 2014). 
For each of web density and web richness, we constructed two causal diagrams, one for each

222 year of the study, with the cover of shrubs, sedges and ferns as measures of vegetation structure (each with their own node). For each of these diagrams, we tested goodness of fit using d-sep tests (Shipley 2009). Once we had tested the goodness of fit of the full path model, we simplified the model to a more parsimonious one using a backward selection approach (sensu Ruffell et al. 2014). Backward selection based on minimising AIC was used to simplify each sub-model within the full model (Zuur et al. 2009). Each sub-model was a mixed-effects model fitted with maximum likelihood estimation, and included an endogenous variable as the response and its direct causal parents as predictors. Once all sub-models had been simplified, they were grouped back into a single path model and the fit of this model was tested using generalised multilevel path analysis and d-sep tests as described above.

All analyses were completed using R (R Core Team 2013). For GLMMs we used the glmer

234 function in the package lme4, using a Poisson distribution and log-link function (Bates et al. 235 2014), while for LMMs we used the lme function in the package nlme (Pinheiro et al. 2014). 236 Random effects for all GLMMs and LMMs were sites within blocks (block/site). When used 237 as predictors, count variables were ln-transformed and continuous variables were centred on 238 their means. Response variables were checked for over-dispersion and model residuals were 239 inspected to verify that the data met model assumptions (Zuur et al. 2009). After deciding on 240 the final model for both web abundance and richness, we calculated path coefficients as the 241 estimated slopes of the variables within each of the sub-models (Shipley 2009).

242 Unstandardized path coefficients can be interpreted as the change in the response variable for 243 a one unit change in the predictor variable (Aiken and West 1991). However, in the presence 244 of an interaction, these path coefficients are conditional effects. Because all predictors were 245 centred, the conditional effects can be interpreted as the effect of the predictor on the response 
variable when the interacting predictor is held at its mean value, or in the case of categorical

247 predictors (fire and herbivore exclosure treatments) at the control value (unburnt and open treatments respectively). The interaction term indicates the amount of change in the slope of

249 the regression of the response on the predictor with a one-unit change in the value of the 250 interacting predictor.

Effects of fire and large herbivores on different web types

To test whether different types of webs responded differently to large herbivores and fire, we estimated unstandardized regression coefficients when the density of that web type was substituted for overall web density in the full path diagram. Each of the individual web types was assigned to one of four groups based on similarity of web characteristics - orb webs, sheet webs, lace webs and tangle webs (Fig. 1, Online Resource 3). Such groupings are commonly used in studies of web-building spiders, and while there is some overlap, these categories broadly sort spiders into groups of families (e.g. Halaj et al. 2000). Orb weavers are generally in the families Araneidae, Tetragnathidae, and Uloboridae, sheet weavers in the

261 families Linyphiidae, Theridiidae and Stiphidiidae, lace weavers belong to Desidae, and 262 tangle web spinners are generally in the family Theridiidae (Online Resource 3). We used a separate GLMM for each web type grouping in each year with a Poisson distribution and log-

264 link function and random effects of block/site. We used backward selection as described above to simplify the model for each web type in each year.

We also analysed the effect of our treatments on the composition of individual web types using partial (or conditioned) canonical correspondence analysis in R (R Core Team 2013),

269 using the "cca" function in the package "vegan" (Oksanen et al. 2013), and using the Bray-

270 Curtis dissimilarity measure. This analysis allowed us to partial out the spatial variation 
associated with the experimental blocks, before analysing the variation in web type composition that was associated with our experimental treatments (herbivory $\times$ fire $\times$ year) (Borcard et al. 1992). We then ran permutation tests using the function "anova.cca" to test the significance of our constraints (treatment combinations) using 10000 permutations of the data. To reduce the incidence of zero values in the data caused by rare web types, we pooled web counts to the site level for this analysis and excluded web types occurring at two or fewer sites.

\section{Results}

Density and richness of spider webs

We counted 3687 spider webs, representing 28 different web types, across the two sampling periods (Online Resource 3). Generalised multilevel path analysis indicated that herbivores and fire affected spider web density via both vegetation-mediated and other pathways, but effects on web type richness were of short duration and not mediated by changes in vegetation.

For web density, the simplified path models $\left(2012: \chi^{2}=34.7, \mathrm{df}=30, \mathrm{P}=0.25,2013: \chi^{2}=\right.$ 29.0, $\mathrm{df}=28, \mathrm{P}=0.41)$ gave as good fit as the full models $\left(2012: \chi^{2}=25.9, \mathrm{df}=22, \mathrm{P}=0.26\right.$, 2013: $\left(\chi^{2}=28.5, \mathrm{df}=22, \mathrm{P}=0.16\right)$ in both years. The simplified model for web density in 2012 indicated that fire had a strong negative effect on web density, which was partly mediated by negative effects of fire on vegetation cover (Fig. 3a). In contrast, the small, but significant, negative effect of large herbivores on web density was not mediated by changes in vegetation structure. By 2013, the effects of fire on vegetation variables were weaker, which was associated with a recovery in vegetation (Fig. 3b). Both the vegetation-mediated effects, and the other effects, of fire on web-density were reduced in 2013 compared with 2012. 
While the effect of fire on shrub cover was reduced in 2013, shrub cover remained a strong determinant of web density in 2013. In 2013 there also was a marginally significant interaction between fire and herbivores, where herbivore activity was positively associated with fern cover in burnt, but not in unburnt sites (Fig. 3b, Online Resource 2 - Figs. OR3a,b). High fern cover was associated with higher web density in the path model (Fig. 3a). As in 2012, in 2013 there was a small negative effect of herbivores on web density which was not explained by vegetation structure. Sensitivity analysis indicated that including all vegetation variables in the path model did not increase the amount of variation in web density that was explained by vegetation-mediated pathways (Online Resource 2).

Model fits for web type richness were similar to those for web density, where our simplified model (2012: $\left.\chi^{2}=35.6, \mathrm{df}=34, \mathrm{P}=0.39,2013: \chi^{2}=30.2, \mathrm{df}=34, \mathrm{P}=0.65\right)$ gave as good a 308 fit as the full model $\left(2012: \chi^{2}=23.8, \mathrm{df}=22, \mathrm{P}=0.35,2013: \chi^{2}=25.0, \mathrm{df}=22, \mathrm{P}=0.30\right)$ in both years of the study. The simplified path models indicated that the effects of disturbance on web-type richness were not mediated by changes in vegetation structure (Fig. 3c,d). Fire

311 had a short-term negative effect on web-type richness which was no longer evident in 2013

312 (15 months after fire). Large herbivores had a small negative effect on web-type richness in 313 both years, and this effect was strongest in 2012, when herbivore activity was elevated in

314 burnt sites (Fig. 3c,d). As with web density, including all vegetation variables in the path 315 analysis did not increase the strength of vegetation-mediated effects on web type richness 316 (Online Resource 2).

Responses of different web types

319 Substituting different web type groupings into the full model in place of web density revealed 320 key differences in the factors affecting different types of webs. Orb web density was higher 


\section{Discussion}

343 We used a combination of burning and herbivore exclusion treatments to test the combined

344 effects of fire and large herbivores on web-building spiders in a forest understory. Fire and

on sites with higher shrub cover, a relationship which mediated the negative effects of fire on orb webs in both years (Table 1). In 2013, orb webs also were positively associated with higher fern cover. In contrast, while some of the effects of fire on sheet webs were vegetationmediated, there was a strong negative effect of fire on sheet webs in both 2012 and 2013, which was not vegetation mediated (Table 1). Sheet webs also responded negatively to herbivore activity on both years, a response which was also not explained by changes in vegetation. Tangle webs and lace webs showed only weak or inconsistent responses to the experimental treatments, with tangle webs showing a shrub-mediated negative response to fire and a negative response to herbivore activity in 2012, but no responses to disturbance in 2013 (Table 1)

Compositional differences in web-types reflected the strongest effects in the analysis of web types. The first two axes of the partial CCA analysis accounted for $14.8 \%$ and $12.4 \%$ of the variation in web type composition, respectively. There was a significant interaction between year and burning treatment $(\mathrm{P}=0.03$, Fig. 4$)$. There were also significant differences in web type composition between burning treatments $(\mathrm{P}<0.01)$, and years $(\mathrm{P}<0.01)$, but not between herbivory treatments or any of its interaction terms (all $\mathrm{P}>0.05$ ). The composition of burnt sites appeared to be a sub-set of unburnt sites, with the two most common sheet webs (web 25 and 27, belonging to the families Theridiidae and Linyphiidae respectively), strongly associated with unburnt sites (Fig. 4).

$$
\text { large herbivores interacted via a chain effect, where fire increased herbivore activity, which in }
$$


turn affected the web-building spider assemblage. Fire and large herbivores also interacted via vegetation-mediated pathways to affect spiders, although this interaction was only marginally significant. The extent to which vegetation structure mediated disturbance effects and the importance of interactive effects differed for web density and richness, and also between web types. Strong effects of disturbance on web-building spiders that were not mediated by vegetation indicate that managing disturbances to maintain vegetation structure is unlikely to 352 adequately address the needs of fauna in this system.

\section{Fire, but not herbivore effects on web density were vegetation-mediated}

Web density was most strongly affected by fire, and much of this effect was mediated by

356 changes in vegetation structure. The loss and subsequent recovery of vegetation after fire

357 (Fig. 3) was mirrored by a loss and partial recovery of spider web density, with spiders likely

358 responding to changes in web-site availability and litter accumulation that occurred with

359 changes in vegetation cover (Brennan et al. 2006; Podgaiski et al. 2013). However, fire also

360 had strong effects on web density that were not explained by vegetation responses, and these

361 effects persisted in the second year of the study (Fig. 3a,b). As our experimental burns were

362 small $(50 \times 50 \mathrm{~m})$, and many spiders are able to rapidly disperse via aerial ballooning (Bell et

363 al. 2005; Langlands et al. 2011), this strong residual effect of fire is unlikely to be limited by

364 recolonization ability. We suggest that other changes that can occur after fire, but were not

365 measured this study, such as reduced soil/litter moisture, or reduced abundances of arthropod

366 prey, may have limited the re-establishment of high densities of spiders following fire

367 (Neumann and Tolhurst 1991; York 1999).

369 Fire and large herbivores interacted to increase the cover of ferns, which had a weak positive

370 effect on web density. This interaction likely occurred due to selective browsing by 
371 herbivores allowing the less palatable bracken to dominate in burnt, browsed environments

372 (Augustine and McNaughton 1998). This increased cover of ferns was positively associated

373 with web density, with fern cover likely providing suitable web sites in an environment where

374 cover of other lifeforms remained low (Online Resource 4). Overall, very little of the effect of

375 large herbivores on spiders was mediated by vegetation, which contrasts with a number of

376 previous studies, which have attributed negative effects of large herbivores on spiders to

377 changes in vegetation structure (e.g. Miyashita et al. 2004; Warui et al. 2005).

379 Path analysis revealed that large herbivores negatively affected web density (and also web

380 type richness) via non-vegetation-mediated pathways, likely through the physical disturbance

381 of webs. Web damage is one of the main triggers for a spider to abandon a web site (Chmiel 382 et al. 2000). Repeated web disturbance may therefore have reduced web density by causing 383 spiders to move out of sites with high herbivore activity, or by reducing spider fitness, as 384 spiders which move web sites must expend considerable energy in web reconstruction 385 (Rypstra 1983; Chmiel et al. 2000), and are more vulnerable to predation when moving 386 between sites (Lubin et al. 1993). The effect of herbivores on web density was greatest in 3872012 (Fig. 3a) and this was likely due to the chain interaction between fire and herbivores, 388 where herbivore activity was higher in burnt sites. This type of interaction has been reported 389 by many previous studies, where burning focusses herbivore activity in burnt patches (Klop et 390 al. 2007; Allred et al. 2011). This greater level of herbivore activity in recently burnt sites 391 would have led to greater rates of web disturbance, and hence the stronger negative effects on 392 spiders. 
395 In contrast to web density, the effects of disturbance on web type richness were of short 396 duration and were not mediated by effects on vegetation structure (Fig. 3c,d). The short-lived 397 effect of fire suggests that spiders were able to rapidly re-colonise sites as the vegetation 398 recovered from fire, a result that is not surprising given the small scale of the burns in our 399 study $(50 \times 50 \mathrm{~m})$ and the high capacity of spiders to disperse via both ground movement and 400 aerial ballooning (Bell et al. 2005; Langlands et al. 2011). Such short-term effects of fire on spider richness are consistent with previous studies from fire-prone environments, where post402 fire recovery of spiders can be rapid (e.g. Brennan et al. 2006; Podgaiski et al. 2013). Spider 403 richness also was directly affected by herbivore activity, where sites with higher herbivore 404 activity had slightly (but significantly) lower web richness (Fig. 3a). This is likely due to a 405 few web types being particularly vulnerable to physical disturbance, causing them to occur 406 only rarely on sites with high herbivore activity.

409 Different web types showed clear differences in their response to fire, large herbivores, and 410 their interaction. Orb web weavers showed a strong post-fire recovery which was largely 411 mediated by vegetation, while sheet web weavers showed a strong negative response to fire, 412 with little recovery after 15 months. These differences are attributable to key differences in 413 the ecology of these different types of web spinners. Firstly, orb weavers tend to build their 414 webs in higher strata of the vegetation than sheet weavers (Janetos 1982), and so are more 415 likely to be able to escape being killed by a low intensity fire. Second, orb weavers tend to 416 have high dispersal capabilities, allowing them to re-colonise rapidly following disturbance 417 (Bell et al. 2005). Third, sheet weavers often have a high proportion of litter arthropods in 418 their diets, compared with orb weavers which target aerial prey (Harwood et al. 2003). 
Therefore, the dry litter conditions which usually occur after fire may have supported low

420 abundances of the decomposers which are key prey items for sheet weavers (Neumann and

421 Tolhurst 1991; York 1999). Fourth, orb webs are more efficient at prey capture than sheet

422 webs (Zschokke et al. 2006), and so orb-web weavers may be able to persist with low post-

423 fire prey densities than sheet web builders. Finally, orb web builders may be better able to use

424 the post-fire vegetation than sheet web builders. Orb weavers responded positively to the

425 recovery of fern cover in burnt sites in 2013, which likely allowed their rapid recovery after

426 fire. In contrast sheet web density was negatively related to the cover of ferns. An abundance

427 of ferns may provide suitable structure for orb weavers to build webs spanning open spaces

428 (Rypstra 1983; Halaj et al. 2000), but may not provide sufficient ground-level structure for

429 sheet webs (Janetos 1982, pers. obs.).

430

431 While orb weavers, sheet weavers and tangle weavers all responded negatively to the high

432 level of herbivore activity in burnt sites in 2012, sheet weavers were the only group to show a 433 consistent negative response in 2013, when herbivore activity was lower. Many sheet webs

434 are larger than tangle and lace webs, are constructed between, rather than within, plants, and 435 are built close to the ground (e.g. web 28, Fig. 1b), all of which would make them vulnerable 436 to trampling and physical disturbance by herbivores. Further, sheet webs have lower rates of 437 prey capture than orb webs, as well as greater costs of initial web construction (Zschokke et 438 al. 2006), which may cause sheet weavers to be more likely to abandon a site after web 439 disturbance (Chmiel et al. 2000). As sheet web building spiders were more strongly affected 440 by disturbance and were slower to recover than other types of web builders, disturbance 441 caused a shift in the composition of this important predator guild. As different types of webs 442 target different types of arthropod prey (Nyffeler 1999; Harwood et al. 2003), these 443 compositional changes to the spider assemblage could have important cascading effects 
444 through the arthropod food web. Understanding how the effects we observed for spiders affect

445 the rest of the arthropod community therefore remains a key area for future research.

\section{Conclusions}

448 Our study has shown that fire and large herbivores can interact both via vegetation-mediated 449 pathways, and via chain effects, to affect web-building spiders, an important component of 450 the forest understory fauna. In our study system, the use of prescribed fire in areas with high 451 densities of native herbivores could lead to reduced densities and altered composition of web452 building spiders, with potential cascading effects through arthropod food webs (Riechert and 453 Lockley 1984; Carter and Rypstra 1995). Managing the ecosystem to reduce the effects of

454 herbivores on vegetation post-fire (i.e. managing the interaction modification) may be 455 ineffective in mitigating the combined effects of disturbance, as the chain effect of fire on 456 herbivore activity also had important short-term effects on spiders. Our results reinforce the 457 importance of considering both independent and interactive effects, as well as the different 458 types of interactions, when managing disturbance regimes (Wisdom et al. 2006; Didham et al. 459 2007; Crain et al. 2008).

The differing strength of vegetation-mediated pathways between web types observed in our study revealed the importance of understanding the mechanisms driving effects for both 463 predicting interactions and managing disturbance effects (Didham et al. 2007; Crain et al. 464 2008). In this system, monitoring and managing the effects of disturbance on vegetation (a 465 common approach to management of disturbances such as fire (Clarke 2008)), is unlikely to 466 detect or prevent important changes in the spider assemblage. Understanding of mechanistic 467 pathways is also essential if studies are to be used to inform management in un-studied 468 locations (Ruffell et al. 2014). To identify the mechanisms driving disturbance interactions, 
long-term, multi-taxon studies, which simultaneously address multiple stressors, will be needed (Tylianakis et al. 2008; Foster et al. 2014). When applied to such studies, analytical approaches such as path analysis will give valuable insights into the importance of different interaction pathways. This mechanistic understanding will be useful, not only in predicting the outcomes of interacting disturbance drivers, but also in identifying appropriate actions to manage their effects on biodiversity (Didham et al. 2007; Crain et al. 2008).

\section{Acknowledgements}

Staff at Booderee National Park conducted prescribed burns. Chris Macgregor assisted with fence construction and plant identification. Many volunteers assisted with data collection. Chloe Sato provided valuable feedback on the manuscript. The Margaret Middleton Fund, The Norman Wettenhall Foundation and the Long Term Ecological Research Network provided financial support. The experiments comply with the current laws of Australia where the research was performed (ANU Animal Ethics protocol A2012/24 and Booderee National Park Research Permit BDR12/00005).

\section{References}

Aiken LS, West SG (1991) Multiple regression: Testing and interpreting interactions. Sage Publictions, Newbury Park, USA

Allred BW, Fuhlendorf SD, Engle DM, Elmore RD (2011) Ungulate preference for burned patches reveals strength of fire-grazing interaction. Ecol. Evol. 1:132-144 of plant communities: Herbivore selectivity and plant tolerance. J. Wildl. Manage. 
Bailey JK, Whitham TG (2002) Interactions among fire, aspen, and elk affect insect diversity: Reversal of a community response. Ecology 83:1701-1712

Barton P, Ikin K, Smith A, MacGregor C, Lindenmayer D (2014) Vegetation structure moderates the effect of fire on bird assemblages in a heterogeneous landscape. Landscape Ecol. 29:703-714

Barton PS, Manning AD, Gibb H, Wood JT, Lindenmayer DB, Cunningham SA (2011) Experimental reduction of native vertebrate grazing and addition of logs benefit beetle diversity at multiple scales. J. Appl. Ecol. 48:943-951

Bates D, Maechler M, Bolker B, Walker S (2014) lme4: Linear mixed-effects models using Eigen and S4, R package version 1.1-7, http://CRAN.R-project.org/package=lme4

Bell JR, Bohan DA, Shaw EM, Weyman GS (2005) Ballooning dispersal using silk: world fauna, phylogenies, genetics and models. Bull. Entomol. Res. 95:69-114

Bell JR, Wheater CP, Cullen WR (2001) The implications of grassland and heathland management for the conservation of spider communities: a review. J. Zool. 255:377-387

Bond WJ, Keeley JE (2005) Fire as a global 'herbivore': The ecology and evolution of flammable ecosystems. Trends Ecol. Evol. 20:387-394

Borcard D, Legendre P, Drapeau P (1992) Partialling out the spatial component of ecological variation. Ecology 73:1045-1055

Brennan KEC, Ashby L, Majer JD, Moir ML, Koch JM (2006) Simplifying assessment of forest management practices for invertebrates: How effective are higher taxon and habitat surrogates for spiders following prescribed burning? For. Ecol. Manage. 231:138-154

Buddle CM, Spence JR, Langor DW (2000) Succession of boreal forest spider assemblages following wildfire and harvesting. Ecography 23:424-436 
Carter PE, Rypstra AL (1995) Top-down effects in soybean agroecosystems: Spider density affects herbivore damage. Oikos 72:433-439

Chmiel K, Herberstein ME, Elgar MA (2000) Web damage and feeding experience influence web site tenacity in the orb-web spider Argiope keyserlingi Karsch. Anim. Behav. $60: 821-826$

Clarke MF (2008) Catering for the needs of fauna in fire management: science or just wishful thinking? Wildl. Res. 35:385-394

Côté SD, Rooney TP, Tremblay JP, Dussault C, Waller DM (2004) Ecological impacts of deer overabundance. Annu. Rev. Ecol., Evol. Syst. 35:113-147

Crain CM, Kroeker K, Halpern BS (2008) Interactive and cumulative effects of multiple human stressors in marine systems. Ecol. Lett. 11:1304-1315

Danell K, Bergström R, Duncan P, Pastor J (2006) Large Herbivore Ecology, Ecosystem Dynamics and Conservation. Cambridge University Press, Cambridge

Dexter N, Hudson M, James S, MacGregor C, Lindenmayer DB (2013) Unintended consequences of invasive predator control in an Australian forest: Overabundant wallabies and vegetation change. PloS ONE 8:e69087

Dexter N, Ramsey DL, MacGregor C, Lindenmayer D (2012) Predicting ecosystem wide impacts of wallaby management using a fuzzy cognitive map. Ecosystems 15:13631379

Didham RK, Tylianakis JM, Gemmell NJ, Rand TA, Ewers RM (2007) Interactive effects of habitat modification and species invasion on native species decline. Trends Ecol. Evol. $22: 489-496$

Foord SH, Dippenaar-Schoeman AS, Stam EM (2013) Surrogates of spider diversity, leveraging the conservation of a poorly known group in the Savanna Biome of South Africa. Biol. Conserv. 161:203-212 
542 Foster CN, Barton PS, Lindenmayer DB (2014) Effects of large native herbivores on other $543 \quad$ animals. J. Appl. Ecol. 51:929-938

544 Gollan JR, Smith HM, Bulbert M, Donnelly AP, Wilkie L (2010) Using spider web types as a 545 substitute for assessing web-building spider biodiversity and the success of habitat 546 restoration. Biodivers. Conserv. 19:3141-3155

547 Halaj J, Ross DW, Moldenke AR (2000) Importance of habitat structure to the arthropod 548 food-web in Douglas-fir canopies. Oikos 90:139-152

549 Halme P et al. (2013) Challenges of ecological restoration: Lessons from forests in northern 550 Europe. Biol. Conserv. 167:248-256

551 Harwood JD, Sunderland KD, Symondson WOC (2003) Web-location by linyphiid spiders: prey-specific aggregation and foraging strategies. J. Anim. Ecol. 72:745-756

553 Hobbs RJ, Huenneke LF (1992) Disturbance, diversity, and invasion: Implications for 554 conservation. Conserv. Biol. 6:324-337 Sociobiol. 10:19-27

Kerns BK, Buonopane M, Thies WG, Niwa C (2011) Reintroducing fire into a ponderosa pine forest with and without cattle grazing: understory vegetation response. Ecosphere 2:art59 
Kimuyu DM, Sensenig RL, Riginos C, Veblen KE, Young TP (2014) Native and domestic browsers and grazers reduce fuels, fire temperatures, and acacia ant mortality in an African savanna. Ecol. Appl. 24:741-749

Klop E, van Goethem J, de Iongh HH (2007) Resource selection by grazing herbivores on post-fire regrowth in a West African woodland savanna. Wildl. Res. 34:77-83

Langellotto G, Denno R (2004) Responses of invertebrate natural enemies to complexstructured habitats: a meta-analytical synthesis. Oecologia 139:1-10

Langlands PR, Brennan KEC, Framenau VW, Main BY (2011) Predicting the post-fire responses of animal assemblages: Testing a trait-based approach using spiders. J. Anim. Ecol. 80:558-568

Lindenmayer D, MacGregor C, Dexter N, Fortescue M, Beaton E (2014) Booderee National Park, The Jewel of Jervis Bay. CSIRO Publishing, Collingwood, Australia

Lubin Y, Ellner S, Kotzman M (1993) Web relocation and habitat selection in desert widow spider. Ecology 74:1915-1928

Mantyka-pringle CS, Martin TG, Rhodes JR (2012) Interactions between climate and habitat loss effects on biodiversity: a systematic review and meta-analysis. Global Change Biol. $18: 1239-1252$

Matlack RS, Kaufman DW, Kaufman GA (2001) Influence of grazing by bison and cattle on deer mice in burned tallgrass prairie. Am. Midl. Nat. 146:361-368

Miyashita T, Takada M, Shimazaki A (2004) Indirect effects of herbivory by deer reduce abundance and species richness of web spiders. Ecoscience 11:74-79

Neumann FG, Tolhurst K (1991) Effects of fuel reduction burning on epigeal arthropods and earthworms in dry sclerophyll eucalypt forest of west-central Victoria. Aust. J. Ecol. $16: 315-330$

Nyffeler M (1999) Prey selection of spiders in the field. J. Arachnol. 27:317-324 
Ohgushi T (2005) Indirect interaction webs: Herbivore-induced effects through trait change in plants. Annu. Rev. Ecol., Evol. Syst. 36:81-105

Oksanen J et al. (2013) vegan: Community Ecology Package, R package version 2.0-10. URL $\underline{\text { http://CRAN.R-project.org/package= }=\text { vegan }}$

Pedersen S et al. (2014) Relationships between native small mammals and native and introduced large herbivores. Austral Ecol. 39:236-243

Pinheiro J, Bates D, DebRoy S, Sarkar D, R Core Team (2014) nlme: Linear and nonlinear mixed effects models, R package version 3.1-118, http://CRAN.Rproject.org/package $=$ nlme

Podgaiski LR et al. (2013) Spider trait assembly patterns and resilience under fire-induced vegetation change in South Brazilian grasslands. PLoS ONE 8:e60207

R Core Team (2013) A language and environment for statistical computing. R Foundation for Statistical Computing, Vienna, Austria. URL http://www.R-project.org/

Riechert SE, Lockley T (1984) Spiders as biological control agents. Annu. Rev. Entomol. 29:299-320

Royo AA, Collins R, Adams MB, Kirschbaum C, Carson WP (2010) Pervasive interactions between ungulate browsers and disturbance regimes promote temperate forest herbaceous diversity. Ecology 91:93-105

Ruffell J et al. (2014) Discriminating the drivers of edge effects on nest predation: Forest edges reduce capture rates of ship rats Rattus rattus, a globally invasive nest predator, by altering vegetation structure. PLoS ONE 9:e113098

Rypstra A (1983) The importance of food and space in limiting web-spider densities; a test using field enclosures. Oecologia 59:312-316

Schmitz OJ (2008) Effects of predator hunting mode on grassland ecosystem function. Science 319:952-954 
616 Shipley B (2002) Cause and correlation in biology: a user's guide to path analysis, structural equations and causal inference, Second edition. Cambridge University Press, Cambridge, U.K.

Shipley B (2009) Confirmatory path analysis in a generalized multilevel context. Ecology $90: 363-368$

Sinclair ARE, Byrom AE (2006) Understanding ecosystem dynamics for conservation of biota. J. Anim. Ecol. 75:64-79

Smit R, Bokdam J, den Ouden J, Olff H, Schot-Opschoor H, Schrijvers M (2001) Effects of introduction and exclusion of large herbivores on small rodent communities. Plant Ecol. 155:119-127

Smith H (2008) BugWise Web2Spider supplement, Available at http://publications.australianmuseum.net.au/pdf/1561_complete.pdf. Accessed 15 October 2012

Specht RL, Morgan DG (1981) The balance between the foliage projective covers of overstorey and understorey strata in Australian vegetation. Aust. J. Ecol. 6:193-202

Thonicke K, Venevsky S, Sitch S, Cramer W (2001) The role of fire disturbance for global vegetation dynamics: Coupling fire into a Dynamic Global Vegetation Model. Global Ecol. Biogeogr. 10:661-677

Tylianakis JM, Didham RK, Bascompte J, Wardle DA (2008) Global change and species interactions in terrestrial ecosystems. Ecol. Lett. 11:1351-1363

636 Underwood EC, Christian CE (2009) Consequences of prescribed fire and grazing on grassland ant communities. Environ. Entomol. 38:325-332 on the spider community of a Kenyan savanna biome. J. Arachnol. 33:269-279 
640 Williams J, Whelan R, Gill A (1994) Fire and environmental heterogeneity in southern

641 temperate forest ecosystems: Implications for management. Aust. J. Bot. 42:125-137

642 Wisdom MJ, Vavra M, Boyd JM, Hemstrom MA, Ager AA, Johnson BK (2006)

643 Understanding ungulate herbivory-episodic disturbance effects on vegetation dynamics:

644 Knowledge gaps and management needs. Wildl. Soc. Bull. 34:283-292

645 York A (1999) Long-term effects of frequent low-intensity burning on the abundance of litter-

646 dwelling invertebrates in coastal blackbutt forests of southeastern Australia. J. Insect

$647 \quad$ Conserv. 3:191-199

648 Zschokke S, Hénaut Y, Benjamin SP, García-Ballinas JA (2006) Prey-capture strategies in

649 sympatric web-building spiders. Canadian Journal of Zoology 84:964-973

650 Zuur AF, Ieno EN, Walker NJ, Saveliev AA, Smith GM (2009) Mixed effects models and

651 extensions in ecology with R. Springer, New York, USA

652 


\section{Tables}

Table 1. Estimated coefficients (and SE) of parameters of the four different types of webs, when substituted for overall web density in the path diagram for 2012 and 2013. All models included the blocking structure of block/site as a random effect. Significance levels: ^ $\mathrm{P} \leq 0.1, * \mathrm{P} \leq 0.05$,

$* * \mathrm{P} \leq 0.01, * * * \mathrm{P} \leq 0.001$

\begin{tabular}{|c|c|c|c|c|c|c|c|c|}
\hline \multirow[t]{3}{*}{ Model term } & \multicolumn{8}{|c|}{ Estimate (se) } \\
\hline & \multicolumn{2}{|c|}{ Orb webs } & \multicolumn{2}{|c|}{ Sheet webs } & \multicolumn{2}{|c|}{ Tangle webs } & \multicolumn{2}{|c|}{ Lace webs } \\
\hline & 2012 & 2013 & 2012 & 2013 & 2012 & 2013 & 2012 & 2013 \\
\hline Shrub cover & $1.23(0.64)^{\wedge}$ & $2.87(0.63)^{\star \star *}$ & - & - & $2.18(0.77)^{\star *}$ & - & - & $-11.1(4.0)^{\star *}$ \\
\hline Sedge cover & - & - & $2.11(0.37)^{* * *}$ & $-1.34(0.49)^{* *}$ & - & - & - & $-2.9(1.9)$ \\
\hline Fern Cover & $-1.42(0.90)$ & $1.55(0.41)^{\star * *}$ & - & $-1.25(0.45)^{* *}$ & - & - & - & - \\
\hline Fire & $-0.76(0.24)^{* *}$ & - & $-1.6(0.23)^{\star \star *}$ & $-1.84(0.29)^{\star * *}$ & - & $-0.07(0.12)$ & - & - \\
\hline Herbivores & $-0.13(0.08)^{\wedge}$ & - & $-0.19(0.07)^{\star *}$ & $-0.19(0.08)^{*}$ & $-0.17(0.05)^{* * *}$ & $0.02(0.05)$ & - & - \\
\hline Fire * herbivores & - & - & - & - & - & $-0.12(0.07)$ & - & - \\
\hline
\end{tabular}




\section{Figures}

654 Figure 1. Examples of web types encountered in surveys. One example of each of the four groups of web types is shown: (a) web 9, an orb web, (b) web 28, a sheet web, (c) web 23, a lace web and (d) web 32, a tangle web.

Figure 2. Hypothesised causal diagram of the effects of fire and large herbivores on webbuilding spiders. We predicted that the effects of fire and herbivores on spiders would be largely vegetation-mediated, but may also occur via other mechanisms that operate independently of vegetation structure. We also predicted that fire may potentially interact with large herbivores by increasing herbivore activity (an interaction chain), or by modifying the effects of large herbivores (an interaction modification).

Figure 3. The effects of fire, herbivores and their interaction on web-building spider density $(a, b)$ and richness $(c, d)$, and the extent to which these effects were mediated by vegetation. Arrows represent causal paths between the experimental treatments (square boxes) and plant and animal responses (rounded boxes). Path coefficients are unstandardized partial regression coefficients. Dashed arrows indicate non-significant relationships, significance levels of path coefficients: ${ }^{\wedge} \mathrm{P} \leq 0.1, * \mathrm{P} \leq 0.05, * * \mathrm{P} \leq 0.01, * * * \mathrm{P} \leq 0.001$. Herbivore activity was $\mathrm{ln}$ transformed when used as a predictor.

Figure 4. Site scores (linear combinations of variable scores) for axis 1 and 2 of the partial canonical correspondence analysis on the distribution of individual web types with respect to the experimental treatments (burning $\times$ herbivory $\times$ year), after blocking effects had been partialed out. Ellipses indicate one standard deviation from the centroid of each burning $\times$ year treatment combination. Numbers identify individual web types: 1-20 - orb webs, 21-24 
678 lace webs, 25-29 sheet webs, 30-32 tangle webs (see Online Resource 3 for individual

679 descriptions). Overlapping web numbers are replaced with points $(+)$. 

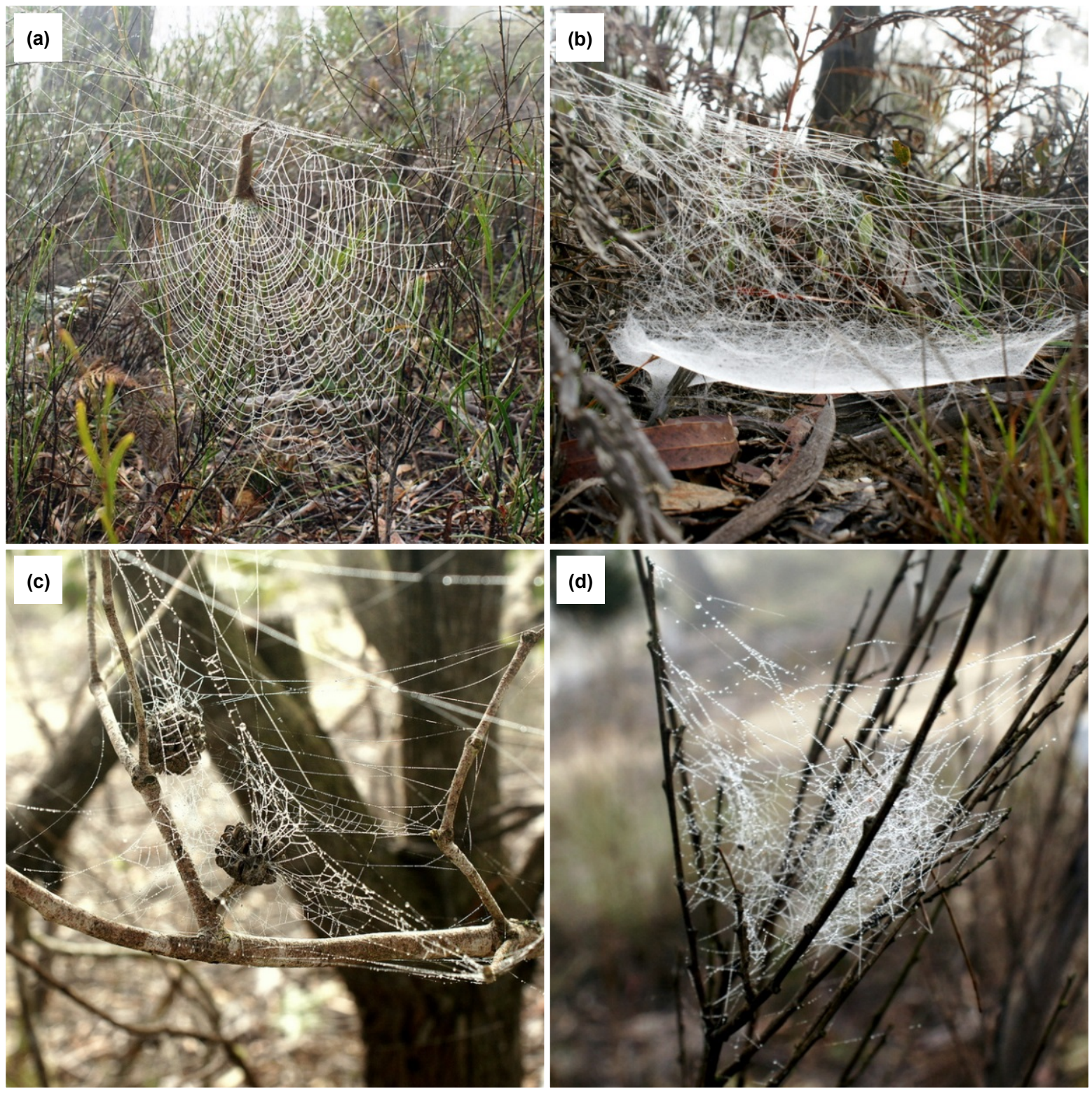

Figure 1. 


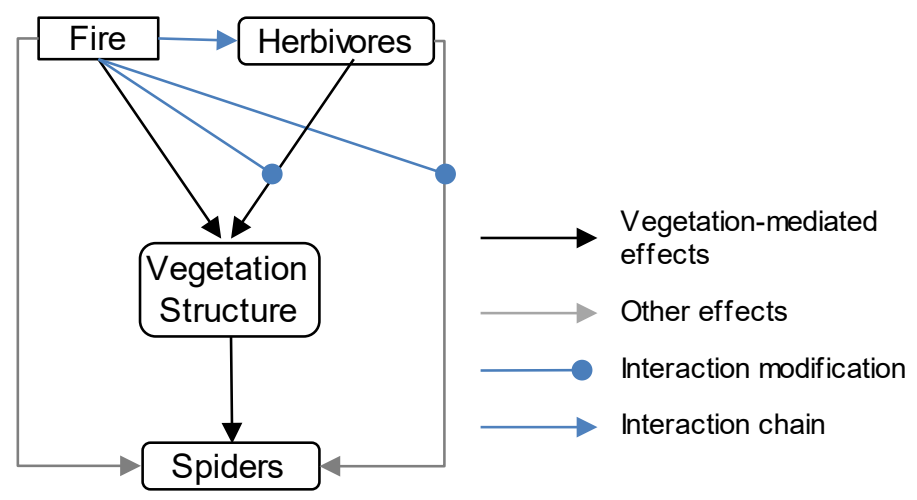

Figure 2. 
(a) Web density 2012

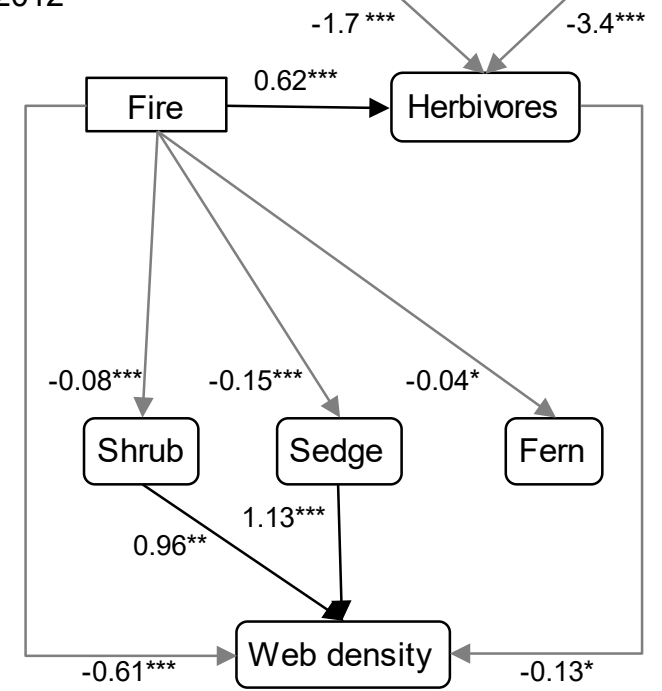

(c) Web type richness 2012

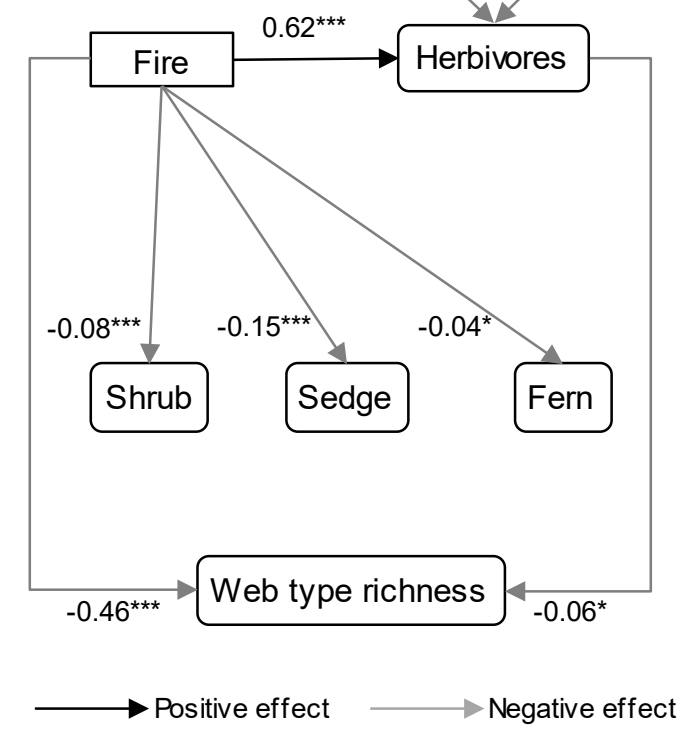

(b) Web density 2013

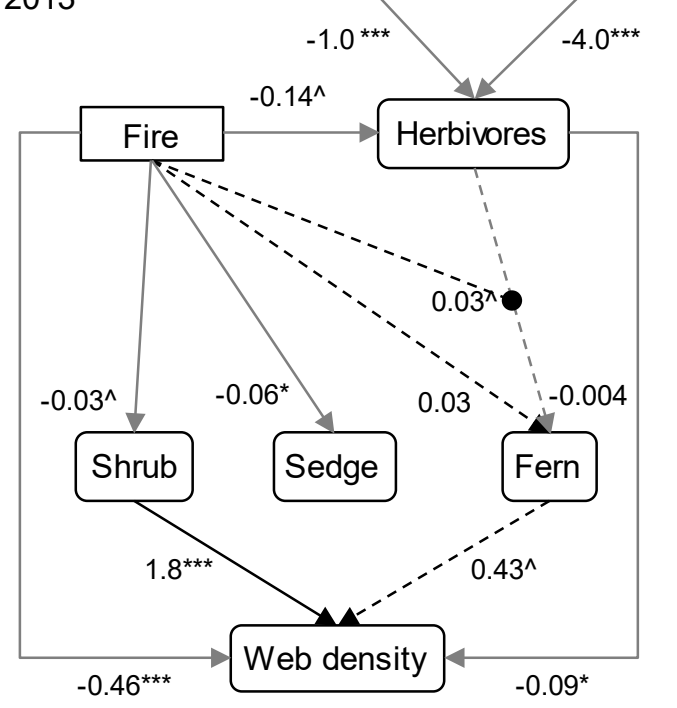

(d) Web type richness Partial Exclosure 2013

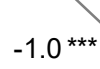
$-4.0^{\star \star \star}$
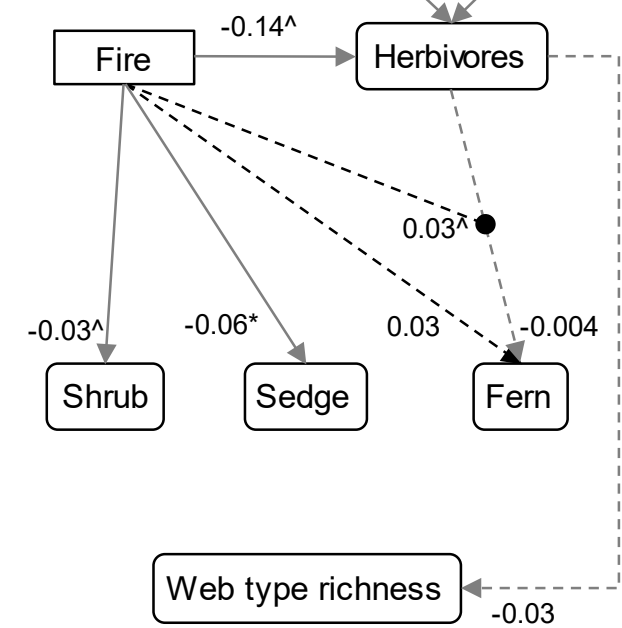

Driver makes effect more negative Driver makes effect more positive

Figure 3. 


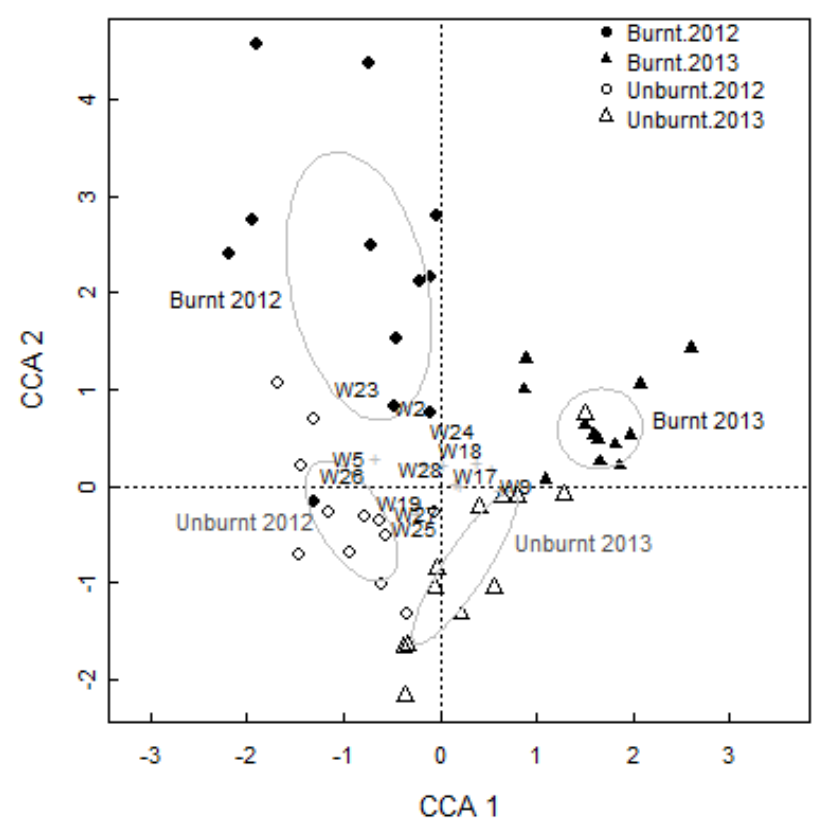

Figure 4. 